\title{
Dietary intake in patients with peripheral arterial disease and concomitant periodontal disease
}

\author{
Anja Horina ${ }^{1 *}$, Behrouz Arefnia ${ }^{2}$, Gernot Wimmer $^{2}$, Marianne Brodmann $^{1}$, Harald Mangge ${ }^{3}$, \\ Robert Gasser ${ }^{4}$, Sandra Holasek ${ }^{5}$, Franz Quehenberger ${ }^{6}$ and Gerald Seinost ${ }^{1}$ \\ ${ }^{1}$ Medical University of Graz, Department of Internal Medicine, Division of Angiology, Auenbruggerplatz 15, 8036 Graz, Austria \\ ${ }^{2}$ Medical University of Graz, Division of Preventive and Operative Dentistry, Endodontics, Pedodontics and Minimally Invasive \\ Dentistry, Auenbruggerplatz 12, 8036 Graz, Austria \\ ${ }^{3}$ Medical University of Graz, Clinical Institute of Medical and Chemical Laboratory Diagnostics, Auenbruggerplatz 15,8036 \\ Graz, Austria \\ ${ }^{4}$ Medical University of Graz, Department of Internal Medicine, Division of Cardiology, Auenbruggerplatz 15, 8036 Graz, \\ Austria \\ ${ }^{5}$ Medical University of Graz, Institute of Pathophysiology and Immunology, Heinrichstrasse 31a, 8010 Graz, Austria \\ ${ }^{6}$ Medical University of Graz, Institute for Medical Informatics, Statistics and Documentation, Auenbruggerplatz 2, 8036 Graz, \\ Austria \\ (Submitted 18 August 2018 - Final revision received 30 March 2019 - Accepted 2 April 2019 - First published online 2 July 2019)
}

\section{Abstract}

Nutrition plays a crucial role in the pathophysiology and management of peripheral arterial disease (PAD) and periodontal disease (PD). As PD can have profound effects on an individual's functional ability to eat and can affect nutrient intake, we aimed to evaluate the role of PD severity on dietary intake (DI) and quality in PAD patients and compare it with current dietary recommendations for CVD. PD stages of 421 consecutive PAD patients were determined according to a standardised basic periodontal examination (Periodontal Screening and Recording Index) ('healthy', 'gingivitis', 'moderate periodontitis' and 'severe periodontitis'). Dietary intake (24-h recall), dietary quality (food frequency index (FFI)) and anthropometrical data were assessed. Nutritional intake was stratified according to the severity of PD. No significant differences in DI of macronutrients, nutrients relevant for CVD and FFI were seen between the PD stages. Only median alcohol intake was significantly different between gingivitis and severe periodontitis $(P=0 \cdot 001)$, and positively correlated with PD severity $(P=0 \cdot 001$; $r 0 \cdot 159)$. PD severity and the patient's number of teeth showed no correlation with investigated nutritional parameters and FFI. Few subjects met the recommended daily intakes for fibre (5\%), SFA (10\%), Na (40\%) and sugar (26\%). Macronutrient intake differed from reference values. In our sample of patients with PAD and concomitant PD, we found no differences in DI of macronutrients, nutrients relevant for CVD and diet quality depending on PD severity. The patients' nutrition was, however, poor, deviating seriously from dietary guidelines and recommendations.

Key words: Dietary intake: Diet quality: Peripheral arterial disease: Periodontal disease: CVD: Food frequency questionnaires

There is an epidemiological association between peripheral arterial disease (PAD) and periodontal disease (PD) ${ }^{(1-3)}$, both of which are aggravated by inflammatory processes ${ }^{(4,5)}$. Nutritional factors influence this significant inflammatory burden in affected individuals ${ }^{(6)}$. PAD patients experience a high risk of ischaemic events ${ }^{(5)}$ and so need adequate secondary prevention strategies. These include modification of dietary habits ${ }^{(7)}$, since a growing body of evidence emphasises the role of nutrition in the pathophysiology and management of both $\mathrm{PAD}^{(8-18)}$ and $\mathrm{PD}^{(19-21)}$. PAD patients in particular are poorly nourished, with an insufficient intake of fibre ${ }^{(8,15)}$, vitamin $\mathrm{E}^{(8-10)}$, folic $\operatorname{acid}^{(8,10)}$ and $n-3$ PUFA $^{(10,15)}$ and high intakes of $\mathrm{Na}^{(8,15)}$, cholesterol ${ }^{(8,15)}$ and saturated fat ${ }^{(8,15)}$.

Poor oral health is a common condition, especially among the elderly, and is associated with an increased risk for atherosclerotic $\mathrm{CVD}^{(3)}$. PD causes chewing discomfort, impairs the

Abbreviations: ACC, American College of Cardiology; AHA, American Heart Association; CHO, carbohydrate; DI, dietary intake; ESC, European Society of Cardiology; FFI, food frequency index; PAD, peripheral arterial disease; PD, periodontal disease; PSR, Periodontal Screening and Recording; TEI, total daily energy intake.

* Corresponding author: Anja Horina, email anja.horina@hotmail.com 
functional ability to eat and negatively affects diet quality and the intake of essential nutrients ${ }^{(22,23)}$. Such patients show a reduced intake of vitamin $\mathrm{C}$, folic acid, $\mathrm{Mg}$ and fibre as compared with healthy controls ${ }^{(24)}$. Individuals with impaired oral health avoid foods that are difficult or painful to chew ${ }^{(23,25)}$. These foods include fresh vegetables and fruit, nuts, seeds and whole grain products, among others, which are sources of essential nutrients and dietary fibre ${ }^{(23)}$.

Since the impact of PD severity on dietary intake (DI) and quality in patients with CVD has not been elucidated, the present study aimed (1) to evaluate the effect of PD severity on diet quality and DI of nutrients relevant for CVD in patients with PAD and (2) to compare DI of this patient population with the current dietary recommendations for CVD. We hypothesised that the severity of PD in PAD patients influences DI and that the consumption of nutrients relevant to CVD will differ from current dietary guidelines.

\section{Methods}

\section{Study population and design}

The present study evaluated data from a single-centre, prospective, randomised, open trial conducted at the Division of Angiology, Medical University of Graz, Austria, investigating the influence of periodontal therapy on vascular inflammation and function in patients with PAD (PeriPAD trial). PeriPAD was registered as a randomised controlled trial at the Deutsches Register Klinischer Studien (https://drks-neu.uniklinik-freiburg. de/drks_web/) ID: 00004554. The present study was conducted according to the guidelines laid down in the Declaration of Helsinki, and all procedures involving human subjects/patients were approved by the Ethics Committee of the Medical University of Graz, Austria (EK-Nr. 24-456 ex 11/12). Written informed consent was obtained from all subjects/patients. Recruitment took place between March 2013 and January 2015.

Patients who fulfilled the following key inclusion criteria were invited to enrol in the study: written informed consent; current or previously diagnosed symptomatic PAD (Rutherford classification 2-4 (intermittent claudication or rest pain)) and documented luminal stenosis $>70 \%$ on ultrasound or angiography or a history of endovascular or surgical revascularisation; periodontal disease determined by the Periodontal Screening and Recording (PSR) Index; signed informed consent form.

The exclusion criteria were defined as PAD Rutherford category 5 and 6 (tissue damage/loss); no natural teeth present; life expectancy $<6$ months; unstable cerebrovascular disease and CVD; clinically apparent infectious disease (e.g. pneumonia and symptomatic urinary tract infection); systemic inflammatory disease (e.g. chronic inflammatory bowel disease, rheumatoid arthritis, vasculitis by clinical assessment); periodontal treatment within 6 months prior to the study; mouth infection other than periodontitis; uncontrolled diabetes; pregnancy; age $<18$ years.

\section{Clinical examination/testing}

A cohort of 421 consecutive patients was screened for inclusion and exclusion criteria. The study visit was performed in the morning after an overnight fast at the Outpatient Clinic for Preventive Vascular Medicine at the Division of Angiology.
A general medical history was taken. Demographic data, anthropometric data, data on CVD risk factors, medication and pertinent vascular examination records were collected. Blood was sampled to determine circulating biomarkers and blood pressure was measured. The ankle brachial index was measured by trained clinical staff according to current standards and guidelines $^{(26)}$. Symptomatic PAD was defined as ankle brachial index $<0.9$ and intermittent claudication or a history of endovascular or surgical revascularisation.

If PAD was diagnosed and at least one original tooth was present, patients were referred to the Division of Prosthodontics and Periodontology, Dental School, Medical University of Graz, to determine dental inclusion criteria. Patients who met the inclusion criteria were enrolled in the study after providing informed consent.

\section{Blood sampling and biochemical analysis}

A venous blood sample was drawn from an antecubital vein in the morning after an overnight fast. Analysis was performed on campus by the university's certified laboratory to guarantee rapid processing. Laboratory methods or values were not changed during the study. Automated analysers (Cobas ${ }^{\circledR}$ 8000, Roche; ARCHITECT®, Abbott GmbH \& Co. KG; XE 5000®, Sysmex; BNA II nephelometer analyser, Siemens,; IDS-iSYS immunoassay system, IDS) were used to measure serum concentrations of TAG, HDL-cholesterol, total cholesterol, glucose, C-reactive protein, cholesterol/HDL ratio and IL-6. The Friedewald formula was used to determine LDL-cholesterol concentrations. The laboratories were certified according to ISO 9001:2008.

\section{Periodontal examination}

The periodontal screening examination included the assessment of the general oral and dental history, determination of the PSR Index and an orthopantomogram. All dental parameters were assessed by experienced periodontists. PSR is an internationally accepted method to examine the periodontium and to detect periodontal diseases ${ }^{(27,28)}$. Patients were classified according to their PSR stage: 'healthy' (PSR stage 0), 'gingivitis' (PSR stage $1+2$ ), 'moderate periodontitis' (PSR stage 3 ) and 'severe periodontitis' (PSR stage 4).

\section{Dietary assessment}

DI was assessed by 24-h food recall (24-h recall) and a thirty-sixitem self-administered qualitative FFQ. Participants were asked to report their usual consumption frequency of the thirty-six listed food items and categories during the previous 3 months with frequency options ranging from 'almost never or $<1 /$ month' to '>3 times/d'. This recently validated and published, self-administered FFQ has proved to be a good measure of dietary quality in a population of people aged 55 years and older $^{(29)}$. The information derived from our FFQ was used to calculate the food frequency index (FFI). The development of this score has been described elsewhere ${ }^{(29)}$

Since elderly patients sometimes have difficulty filling out questionnaires by themselves, a trained dietitian was available for support, checked the FFQ for completeness and undertook the structured 24-h recall together with the patients. 
Table 1. Patient characteristics ( $n$ 412)

(Mean values and standard deviations; numbers and percentages; median and interquartile range (IQR))

\begin{tabular}{|c|c|c|c|c|}
\hline & Mean & SD & $n$ & $\%$ \\
\hline Age (years) & 63 & 10 & & \\
\hline Height $(\mathrm{cm})$ & 171 & 9 & & \\
\hline Weight (kg) & 80 & 14 & & \\
\hline BMI $\left(\mathrm{kg} / \mathrm{m}^{2}\right)$ & 27 & 4 & & \\
\hline Males & & & 297 & 70 \\
\hline \multicolumn{5}{|l|}{ Smoking status } \\
\hline Never & & & 69 & 17 \\
\hline Former & & & 195 & 47 \\
\hline Current & & & 148 & 36 \\
\hline Hypertension & & & 332 & 81 \\
\hline Obesity & & & 98 & 24 \\
\hline Diabetes & & & 114 & 28 \\
\hline Systolic blood pressure (mmHg)) & 151 & 20 & & \\
\hline Diastolic blood pressure $(\mathrm{mmHg})$ ) & 85 & 11 & & \\
\hline C-reactive protein $(\mathrm{mmol} / \mathrm{l})$ & $2 \cdot 6$ & 4.3 & & \\
\hline IL-6 (pg/ml) & 3.8 & 3.0 & & \\
\hline Glucose (mmol/l) & 111 & 37 & & \\
\hline TAG $(\mathrm{mmol} / \mathrm{l})$ & 120 & 81 & & \\
\hline Cholesterol (mmol/l) & 180 & 47 & & \\
\hline HDL-cholesterol (mmol/l) & 52 & 17 & & \\
\hline LDL-cholesterol (mmol/l) & 99 & 38 & & \\
\hline $\begin{array}{l}\text { Neurological events (haemorrhagic and } \\
\text { ischaemic stroke) }\end{array}$ & & & 44 & 10 \\
\hline CVD (MCl, PCl, CABG) & & & 92 & 22 \\
\hline Vascular intervention (EVR/bypass) & & & 306 & 73 \\
\hline \multicolumn{5}{|l|}{ Ankle brachial index } \\
\hline Median & \multicolumn{2}{|c|}{0.63} & & \\
\hline IQR & \multicolumn{2}{|c|}{0.5} & & \\
\hline Statins & & & 315 & 75 \\
\hline Antithrombotic agent or anticoagulation & & & 43 & 10 \\
\hline $\begin{array}{l}\text { Angiotensin-converting enzyme/angiotensin } \\
\text { receptor blockers }\end{array}$ & & & 271 & 64 \\
\hline Ca receptor antagonists & & & 121 & 29 \\
\hline \multicolumn{5}{|l|}{ Marital status } \\
\hline Single & & & 48 & 11 \\
\hline Married & & & 249 & 58 \\
\hline Compulsory schooling & & & 286 & 68 \\
\hline Completion of secondary education & & & 58 & 14 \\
\hline University degree/further education & & & 30 & 7 \\
\hline
\end{tabular}

$\mathrm{MCl}$, myocardial infarction; $\mathrm{PCl}$, percutaneous coronary intervention; $\mathrm{CABG}$, coronary artery bypass graft; EVR, endovascular revascularisation.

Nutrient intake from 24-h recall was subsequently calculated using nut.s software (nutritional.software, dato Denkwerkzeuge). Our results were compared with the D-A-CH reference values for nutrient supply (German Nutrition Society (DGE), the Austrian Nutrition Society and the Swiss Society for Nutritional Research) ${ }^{(30)}$ and recommendations for CVD prevention of the European Society of Cardiology (ESC) ${ }^{(31)}$ and American Heart Association/American College of Cardiology (AHA/ACC) ${ }^{(32-34)}$.

\section{Statistical analysis}

Statistical analyses were as follows: For descriptive statistics, means and standard deviations were calculated for normally distributed data; otherwise, medians and interquartile ranges (25th-75th percentiles) were calculated (Table 1). Normal distribution of data was tested by the Kolmogorov-Smirnov test. The Kruskal-Wallis test was used to determine differences in nutrient intake (a $P$ value of $<0.007$ was considered statistically significant after Bonferroni correction ${ }^{(35)}$ to account for multiple testing) (Table 2) and in macronutrient consumption (Table 3) between the three periodontal disease groups. Spearman's correlation coefficient was used in correlation analysis. All analyses were completed with SPSS for Windows version 23 (SSCP Inc.)

Recommendations for the intake of specific nutrients were obtained from the guidelines for CVD prevention by the $\mathrm{ESC}^{(31)}$ and $\mathrm{AHA} / \mathrm{ACC}^{(32)}$.

\section{Results}

A total of 807 patients were screened for study inclusion, and 386 patients were not eligible due to various reasons (see Fig. 1). Finally, 421 patients were included for analysis. Nine patients had to be excluded for analysis due to screening failure. Twelve patients had to be excluded due to missing dental data, leaving 400 participants for analysis.

Patients' characteristics are summarised in Table 1. A flow chart of the screening process is shown in Fig. 1.

\section{Impact of periodontal disease severity on dietary intake and quality}

We found a very high prevalence of PD among our PAD patients (99.8\%), of whom $53.9 \%$ ( $n$ 216) were diagnosed with severe periodontitis. Only one of the patients was classified as dentally healthy.

Nutritional intake was stratified according to the severity of PD. No difference in DI of total fibre, cholesterol, $n-3$ PUFA, SFA, sugar and $\mathrm{Na}$ was seen among PAD patients with gingivitis, moderate periodontitis and severe periodontitis. Alcohol consumption differed between PD stages and showed a positive correlation with PD severity $(P=0.001 ; r 0.159)$ (Table 2). Post hoc testing revealed a significant difference in median alcohol intake between patients with gingivitis and severe periodontitis $(P=0 \cdot 001)$.

PD severity and patients' median number of teeth ${ }^{(18,10-24)}$ did not correlate with other investigated nutritional parameters and FFI. The FFI indicated no difference in diet quality among the PD stages.

\section{Impact of periodontal disease severity and number of teeth on macronutrient composition}

The non-parametric Kruskal-Wallis test showed no difference in macronutrient intake between the three PD stages. However, daily macronutrient intake (in \%) differed from D-A-CH reference values for nutrient supply ${ }^{(30)}$. On average, the subjects consumed fewer than the daily reference value of $9204 \mathrm{~kJ} / \mathrm{d}$ for men 51 years of age and older at a physical activity level of $1.4^{(30)}$. Dietary fat intake was well above the recommended $30 \%$ of total daily energy intake (TEI) ${ }^{(30)}$ (Table 3), which $80 \%$ of the participants exceeded. Median daily carbohydrate (CHO) consumption of all subjects was below the recommended intake value (D-A-CH: $50-60 \%$ of $\mathrm{TEI}^{(30)}$ ) with $41.5 \%$ of TEI. Protein intake of this patient population was found to be adequate (Table 3 ). 
Table 2. Dietary intake (24-h recall) of nutrients relevant for CVD and diet quality in peripheral arterial disease patients with gingivitis, moderate periodontitis and severe periodontitis

(Medians and 25th-75th percentiles)

\begin{tabular}{|c|c|c|c|c|c|c|c|}
\hline & \multicolumn{2}{|c|}{ Gingivitis: PSR $1+2$ ( $n$ 122) } & \multicolumn{2}{|c|}{$\begin{array}{c}\text { Moderate periodontitis: } \\
\text { PSR } 3(n 62) \\
\end{array}$} & \multicolumn{2}{|c|}{$\begin{array}{l}\text { Severe periodontitis: } \\
\text { PSR } 4(n 216)\end{array}$} & \multirow[b]{2}{*}{$P^{\star}$} \\
\hline & Median & 25th-75th percentiles & Median & 25th-75th percentiles & Median & 25th-75th percentiles & \\
\hline Total dietary fibre (g) & 17 & $13-24$ & 17 & $12-22$ & 16 & $12-21$ & 0.226 \\
\hline Cholesterol (mg) & 234 & $162-366$ & 291 & $181-426$ & 287 & $176-430$ & 0.037 \\
\hline Dietary $n-3$ PUFA (g) & 1.1 & $0.9-1.7$ & $1 \cdot 3$ & $0.8-1.8$ & $1 \cdot 2$ & $0.9-1.8$ & 0.617 \\
\hline SFA (g) & 35 & $24-46$ & 36 & $22-50$ & 35 & $24-50$ & 0.969 \\
\hline Sugar (g) & 77 & 53-104 & 74 & $34-110$ & 66 & $37-106$ & 0.149 \\
\hline $\mathrm{Na}(\mathrm{mg})$ & 2466 & 1728-3194 & 3105 & $1834-4290$ & 2535 & $1935-3760$ & 0.033 \\
\hline Alcohol (g) & 0 & $0-11$ & 0.1 & $0-18$ & 0.7 & $0-20$ & 0.006 \\
\hline Food frequency index & 30 & $26-33$ & 28 & $26-33$ & 29 & $25-32$ & 0.163 \\
\hline
\end{tabular}

PSR, Periodontal Screening and Recording Index.

* $P$ value was calculated from the Kruskal-Wallis test for continuous variables.

Table 3. Comparison of macronutrient intake among peripheral arterial disease patients with gingivitis, moderate periodontitis and severe periodontitis (Medians and 25th-75th percentiles)

\begin{tabular}{|c|c|c|c|c|c|c|c|c|}
\hline & \multirow[b]{2}{*}{$\begin{array}{l}\text { Reference } \\
\text { values }\end{array}$} & \multicolumn{2}{|c|}{ Gingivitis ( $n$ 122) } & \multicolumn{2}{|c|}{ Moderate periodontitis ( $n$ 62) } & \multicolumn{2}{|c|}{ Severe periodontitis ( $n 216)$} & \multirow[b]{2}{*}{$P \ddagger$} \\
\hline & & Median & $\begin{array}{l}\text { 25th-75th } \\
\text { percentiles }\end{array}$ & Median & $\begin{array}{l}\text { 25th-75th } \\
\text { percentiles }\end{array}$ & Median & $\begin{array}{l}\text { 25th-75th } \\
\text { percentiles }\end{array}$ & \\
\hline Total daily energy intake $(\mathrm{kJ})^{\star}$ & 9204 & 7698 & $6475-9391$ & 8383 & $6385-11335$ & 8072 & 6444-9971 & 0.373 \\
\hline$\%$ Carbohydrates of daily El & $>50 \% \dagger$ & 42 & $38-50$ & 41 & $34-51$ & 41 & $34-48$ & 0.116 \\
\hline$\%$ Fat of daily EI & $<30 \% \dagger$ & 41 & $35-46$ & 38 & $32-47$ & 39 & $31-47$ & 0.456 \\
\hline Protein intake (g/kg BW) & $0.8 \mathrm{~g} / \mathrm{kg} \mathrm{BW}$ & 0.8 & $0.6-1 \cdot 1$ & 1 & $0.7-1 \cdot 2$ & 0.9 & $0.7-1.2$ & 0.220 \\
\hline \% Protein of daily El & $10-15 \% \dagger$ & 15 & $11-17$ & 15 & $12-18$ & 15 & $12-18$ & 0.412 \\
\hline
\end{tabular}

El, energy intake; BW, body weight.

${ }^{*} \mathrm{D}-\mathrm{A}-\mathrm{CH}$ reference values for male subjects, $51-65$ years, physical activity level $=1.4$ was used ${ }^{(30)}$.

$\dagger$ Percentage of daily energy intake.

$\ddagger P$ values were calculated from the non-parametric Kruskal-Wallis test.

\section{Dietary intake relative to recommendations}

Table 4 displays the nutritional intake of patients in comparison with established guidelines for CVD prevention.

The recommended daily amount of $n-3$ PUFA $^{(33,34)}$ was consumed by two-thirds of our patients with both PAD and PD, with $1.7 \%$ of the patients reporting the daily use of $n$ - 3 PUFA supplements. Our subjects showed elevated intake levels of SFA (90\% exceeded the cut-off point of $10 \%$ of TEI, as recommended by the $\left.\mathrm{ESC}^{(31)}\right), \mathrm{Na}$ and sugar. An inadequate intake of total dietary fibre was reported (95\% of subjects did not meet the ESC cutoff $\left.^{(31)}\right)$. Recommendations for alcohol consumption were met by $>70 \%$ of this patient population (Table 4 ).

\section{Discussion}

The main finding of this cross-sectional study was that overall DI of nutrients relevant for CVD and diet quality did not differ depending on the severity of PD in patients with PAD. Nevertheless, macronutrient consumption and intake of nutrients relevant for CVD greatly deviated from current dietary guidelines.

\section{Impact of periodontal disease severity on dietary intake and quality}

Previous studies have reported an impairment of the functional ability to eat in patients affected with PD and poor oral health. This contributed to poor composition and quality of the patient's $\operatorname{diet}^{(23)}$. In a study by Staudte et $a l .{ }^{(24)}$, approximately $50 \%$ of the patients with chronic periodontitis experienced oral discomfort while eating. An individual's dental condition and tooth loss, which may be related to PD, can also influence DI of essential nutrients and the selection of foods consumed ${ }^{(23-25)}$. It could therefore be suspected that patients with a more severe degree of PD would have more trouble chewing and so would not consume enough essential nutrients. Foods difficult to masticate include many with a healthful profile such as fruits, raw vegetables, nuts and whole grain bread, among others ${ }^{(23,25)}$.

In our study, the prevalence of moderate and severe periodontitis in screened patients was $69 \%$, which is similar to what has been reported in the literature ${ }^{(36)}$. Despite this high prevalence of PD among our PAD patients, the degree of PD did not affect diet quality and intake of nutrients relevant for CVD. Nevertheless, we observed a significant difference in alcohol intake between patients with severe periodontitis and those with gingivitis. Alcohol consumption was the only parameter presenting a significant positive correlation with PD severity and has previously been shown to negatively affect $\mathrm{PD}^{(37)}$ and to increase the risk for PAD ${ }^{(17,38)}$.

Number and distribution of natural teeth have also been shown to influence DI, food choice and amount of nutrients consumed, probably due to the reduced ability to chew $^{(22,25)}$, but we did not find any correlation between the number of teeth and PD severity with the nutritional parameters investigated. These contradictory findings might be explained by the fact that the median 


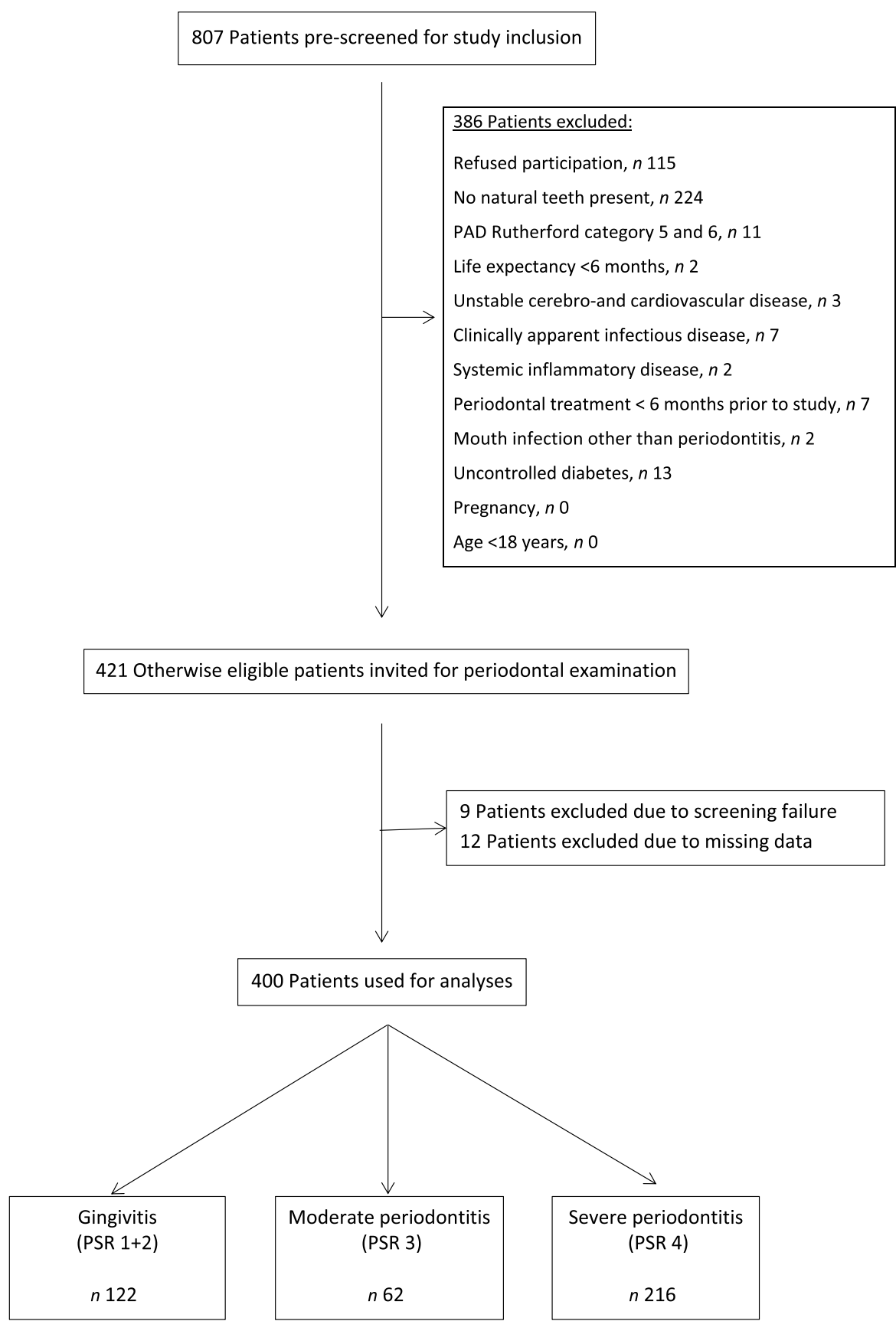

Fig. 1. Flow diagram of the screening process and enrolment of patients. PAD, peripheral arterial disease; PSR, Periodontal Screening and Recording Index.

age of our participants was lower than in Sheiham et al. ${ }^{(25)}$, and the median number of eighteen natural teeth in our patients was still fairly high. Marcenes et al. ${ }^{(25)}$ defined acceptable oral health by the presence of $>20$ natural teeth and stated that subjects with $>21$ teeth consumed more essential nutrients.

\section{Impact of periodontal disease severity and number of teeth on macronutrient composition}

We hypothesised that in PAD patients, concomitant presence of PD alters the composition of the patients' diet. Contrary to expectations, we observed no difference in macronutrient composition among the three PD stages. However, $\mathrm{CHO}$ and fat intake of our patients differed from current reference values. $\mathrm{D}-\mathrm{A}-\mathrm{CH}$ reference values for daily intake of $\mathrm{CHO}$, fat and protein are $50-60 \%, 25-30 \%$ and $10-15 \%$ of TEI, respectively ${ }^{(30)}$.

Protein intake was adequate in our patients, but $\mathrm{CHO}$ intake was far too low in all PD groups. In contrast, $80 \%$ of our patients exceeded the recommended fat intake of $30 \%$ of TEI. This is in agreement with Brostow et al. ${ }^{(12)}$, who showed in sixty-four PAD patients that the percentage of energy consumed as fat also exceeded the recommendations.

Our results stand in contrast to Gardner et al. ${ }^{(8)}$, who examined the DI of forty-six subjects with PAD and reported a mean 
Table 4. Nutrient intake in peripheral arterial disease patients compared with guidelines for CVD prevention* (Medians and 25th-75th percentiles; percentages and numbers of patients meeting recommendations)

\begin{tabular}{|c|c|c|c|c|c|}
\hline \multirow[b]{2}{*}{ Nutrient } & \multirow{2}{*}{$\begin{array}{l}\text { Nutritional guidelines for } \\
\text { CVD prevention }\end{array}$} & \multicolumn{2}{|c|}{ Dietary intake } & \multicolumn{2}{|c|}{$\begin{array}{l}\text { Cohort meeting } \\
\text { recommendations }\end{array}$} \\
\hline & & Median & 25th-75th percentiles & $\%$ & $n / n \dagger$ \\
\hline Dietary $n-3$ PUFA (g) & $1 \mathrm{~g} / \mathrm{d}$ & 1.2 & $0.9-1.7$ & 66 & $269 / 142$ \\
\hline SFA (\% of TEI) & $<10 \%$ & 17 & $13-21$ & 10 & $39 / 372$ \\
\hline $\mathrm{Na}(\mathrm{mg})$ & $<2300 \mathrm{mg}$ & 2610 & $1883-3568$ & 39 & $160 / 251$ \\
\hline Total dietary fibre (g) & $30-45 \mathrm{~g} / \mathrm{d}$ & 16 & $12-21$ & 5 & $19 / 362$ \\
\hline Sugar intake (\% of TEI) & $<10 \%$ & 15 & $10-22$ & 26 & $108 / 303$ \\
\hline Alcohol (g) & Male: maximum 20 g/d & 0.7 & $0-20$ & 76 & $227 / 70$ \\
\hline & Female: maximum $10 \mathrm{~g} / \mathrm{d}$ & 0 & $0-6$ & 78 & $90 / 25$ \\
\hline
\end{tabular}

TEI, total daily energy intake; ESC, European Society of Cardiology; AHA, American Heart Association; ACC, American College of Cardiology.

* The Table summarises the subjects' nutritional intake, represented as proportions (\%) relative to recommendations for nutrient intake. The values used for comparison were obtained from guidelines for CVD prevention by the $\mathrm{ESC}^{(31)}$ and for $\mathrm{Na}$ intake by the AHA/ACC ${ }^{(32)}$. Recommendations for daily dietary $n-3$ PUFA (1 $\left.\mathrm{g} / \mathrm{d}\right)$ from the $\mathrm{AHA}{ }^{(33,34)}$ were used, as the ESC guidelines do not include specific recommendations for dietary $n-3$ PUFA intake. Dietary $n$-3 PUFA refers to total dietary $n-3$ PUFA (i.e. $\alpha$-linolenic acid, EPA, docosapentaenoic acid and DHA).

$\dagger$ Number of patients meeting the recommendations/number of patients not meeting recommendations.

macronutrient composition very close to recommendations (17 $\%$ protein, $51 \% \mathrm{CHO}$ and $30 \%$ fat). Our findings also disagree with Hamasaki et al. ${ }^{(39)}$, demonstrating a low intake of dietary fat in patients with advanced PD $(23 \cdot 2 \pm 7 \cdot 1 \%)$. In this specific study the 'weighting capacity technique' was used to determine DI (with this method, food intake was distributed in proportion to family size by dividing by the number of people in the family) ${ }^{(39)}$. The greater sample size of our investigation and the different methods of dietary assessment might explain the contradictory results. Our representative cross-sectional results might reflect the general DI of the Austrian population ${ }^{(40)}$, with a lower than recommended intake of $\mathrm{CHO}$, but increased intake of dietary fat and adequate intake of protein.

\section{Dietary intake relative to European Society of Cardiology and American Heart Association/American College of Cardiology recommendations}

Strategies for secondary prevention of CVD include the modification of dietary intake and habits. Accordingly, lifestyle and nutritional guidelines for the management of CVD have been developed by various institutions including the $\mathrm{ESC}^{(31)}$, AHA and $\mathrm{ACC}^{(32-34)}$. Specific dietary parameters relevant for CVD, and therefore for patients affected with PAD, include $n-3$ fatty acids, SFA, Na, dietary fibre, sugar intake and alcohol consumption $^{(31-34)}$. The results of the present study demonstrate that the consumption of these nutrients diverged greatly from guidelines.

Several classes of fatty acids have been shown to influence cardiovascular risk factors and outcomes ${ }^{(11)}$. The prospective Prevención con Dieta Mediterránea (PREDIMED) trial showed that the intake of $n-3$ PUFA may be associated with a reduced risk for developing $\mathrm{PAD}^{(41)}$. Generally, PAD patients appear to have an inadequate intake of vegetable lipids and hence essential fatty acids ${ }^{(9)}$. $n$-3 Fatty acids have also been suggested to play a role in PD. Using National Health and Nutrition Examination Survey (NHANES) III data, Naqvi et al. ${ }^{(42)}$ found an inverse association of $n-3$ fatty acid intake with lower prevalence of periodontitis. In our large cohort of $\mathrm{PAD}$ patients suffering from concomitant $\mathrm{PD}$, $66 \%$ reached the AHA/ACC recommendation of at least $1 \mathrm{~g} / \mathrm{d}$ of $n$ - 3 PUFA. A similar result was obtained in a recent prospective study by Nosova et al. ${ }^{(15)}$, who showed that $59 \%$ of their veteran subjects suffering from PAD reached this recommended cut-off. Another previous study by Lane et al. ${ }^{(10)}$ demonstrated the reduced consumption of PUFA among PAD patients and suggested a protective effect of $n-3$ fatty acids against $\mathrm{CAD}$ and PAD.

A low intake of SFA, another class of fatty acids, is also of major importance in CVD prevention. Dietary SFA have been associated with an increased risk for PAD ${ }^{(11)}$. Gardner et al. ${ }^{\left({ }^{8}\right)}$ demonstrated that $80 \%$ of their PAD patients exceeded the recommended DI of SFA. These results are confirmed by our study, where more than $90 \%$ exceeded the recommended upper value.

Adequate fibre intake has previously been shown to have an inverse association with $\mathrm{PAD}^{(18)}$. Our data confirm the findings of Nosova et ll $^{(15)}$, who showed a low intake of fibre and high intake of $\mathrm{Na}$ among their PAD patients. In our cohort poor nutrition was reflected in high intake of $\mathrm{Na}$ and sugar, whereas more than $90 \%$ of our subjects did not reach the recommended intake of dietary fibre. This is in accordance with Gardner et al. ${ }^{(8)}$, who showed that only $26 \%$ of their PAD patients reached the recommended intake for dietary fibre. It reflects a low intake of highfibre foods, such as whole grain products, fruits and vegetables, all of which are difficult to chew. Since our patients were also suffering from PD, this might have further influenced fibre intake. Periodontal inflammation and loose teeth make it difficult to eat high-fibre foods. Staudte et al. ${ }^{(24)}$ also demonstrated a lower intake of fibre in patients with periodontitis than in healthy controls.

The findings of our study highlight important implications for secondary prevention of CVD and public health, although we could not demonstrate that PD influences DI in PAD patients. Nevertheless, these patients should be encouraged to follow the ESC, AHA/ACC and D-A-CH dietary guidelines. Dietary modification and enhancement of nutritional strategies (including management of alcohol intake) should be considered as key components in secondary prevention to reduce CV risk in this population.

\section{Limitations}

There are limitations to this cross-sectional, observational study. The patient population is not representative of a general population since predominately Caucasian PAD patients were 
studied. Furthermore, we did not include PAD patients with Fontaine Stage IV (defined by skin necrosis or ulcers), and our patients were not compared with a healthy control group. Another limitation is that DI was recorded via 1-d 24h-recall and a FFQ. A 7-d dietary recall would have been of advantage to evaluate the patients' dietary intake and habits in more detail, also capturing foods that are not eaten daily (e.g. fish), but was not feasible in our patient population due to age, cognitive impairment and other co-morbidities. Nevertheless, the methods we used are widely accepted tools for dietary assessment and can be a reliable indicator of trends in dietary habits within a population. In addition, to avoid potential errors in DI reporting, a trained dietitian was always available to help patients with the questionnaires.

\section{Conclusion}

In our sample of patients with PAD and concomitant PD, we did not observe differences in DI of nutrients known to be relevant for CVD and diet quality in relation to the severity of the $\mathrm{PD}$, though macronutrient intake did differ from $\mathrm{D}-\mathrm{A}-\mathrm{CH}$ recommendations. Our most relevant finding is that our patients showed poor nutrition with regard to DI of $\mathrm{Na}$, fibre, sugar, $n$-3 fatty acids and SFA, which differed greatly from current recommendations of the ESC, AHA and ACC. Future studies should focus on nutritional modification and intervention in order to study the effect on the progression of PD and CV risk in PAD patients.

\section{Acknowledgements}

We are grateful to the Austrian Science Fund (FWF) for funding and to the patients who were willing to provide their data.

This work was supported by the FWF (grant number KLI 256 B00). The FWF had no role in the design, analysis or writing of this article.

The authors take full responsibility for the content to which they have contributed. A. H., B. A., G. W., B. M., H. M., R. G., S. H., F. Q. and G. S. have no conflict of interest to disclose related to the manuscript. A. H., G. S., G. W., B. A., R. G. were responsible for study design; A. H., G. S., G. W., B. A., B. M. conducted the research; F. Q. and A. H. analysed the data and performed statistical analysis; and S. H. and H. M. were involved in manuscript preparation.

\section{References}

1. Seinost G, Wimmer G, Skerget M, et al. (2005) Periodontal treatment improves endothelial dysfunction in patients with severe periodontitis. Am Heart J 149, 1050-1054.

2. Beukers NG, van der Heijden GJ, van Wijk AJ, et al. (2017) Periodontitis is an independent risk indicator for atherosclerotic cardiovascular diseases among 60174 participants in a large dental school in the Netherlands. J Epidemiol Community Health 71, 37-42.
3. Dietrich T, Webb I, Stenhouse L, et al. (2017) Evidence summary: the relationship between oral and cardiovascular disease. Br Dent J 222, 381-385.

4. Van Dyke TE (2008) The management of inflammation in periodontal disease. J Periodontol 79, 8 Suppl., 1601-1608.

5. Brevetti G, Giugliano G, Brevetti L, et al. (2010) Inflammation in peripheral artery disease. Circulation 122, 1862-1875.

6. Calder PC, Albers R, Antoine J-M, et al. (2009) Inflammatory disease processes and interactions with nutrition. Br J Nutr 101, Suppl. 1, S1-S45.

7. Gerhard-Herman MD, Gornik HL, Barrett C, et al. (2017) 2016 AHA/ACC Guideline on the Management of Patients With Lower Extremity Peripheral Artery Disease: A Report of the American College of Cardiology/American Heart Association Task Force on Clinical Practice Guidelines. Circulation 135, e726-e779.

8. Gardner AW, Bright BC, Ort KA, et al. (2011) Dietary intake of participants with peripheral artery disease and claudication. Angiology 62, 270-275.

9. Antonelli-Incalzi R, Pedone C, McDermott MM, et al. (2006) Association between nutrient intake and peripheral artery disease: results from the InCHIANTI study. Atherosclerosis 186, 200-206.

10. Lane JS, Magno CP, Lane KT, et al. (2008) Nutrition impacts the prevalence of peripheral arterial disease in the United States. $J$ Vasc Surg 48, 897-904.

11. Naqvi AZ, Davis RB \& Mukamal KJ (2012) Dietary fatty acids and peripheral artery disease in adults. Atherosclerosis 222, 545-550.

12. Brostow DP, Hirsch AT, Pereira MA, et al. (2016) Nutritional status and body composition in patients with peripheral arterial disease: a cross-sectional examination of disease severity and quality of life. Ecol Food Nutr 55, 87-109.

13. Brostow DP, Hirsch AT, Collins TC, et al. (2012) The role of nutrition and body composition in peripheral arterial disease. Nat Rev Cardiol 9, 634-643.

14. Nosova EV, Conte MS \& Grenon SM (2015) Advancing beyond the 'heart-healthy diet' for peripheral arterial disease. $J$ Vasc Surg 61, 265-274.

15. Nosova EV, Bartel K, Chong KC, et al. (2015) Analysis of nutritional habits and intake of polyunsaturated fatty acids in veterans with peripheral arterial disease. Vasc Med 20, 432-438.

16. Naqvi AZ, Davis RB \& Mukamal KJ (2014) Nutrient intake and peripheral artery disease in adults: key considerations in crosssectional studies. Clin Nutr 33, 443-447.

17. Ogilvie RP, Lutsey PL, Heiss G, et al. (2017) Dietary intake and peripheral arterial disease incidence in middle-aged adults: the Atherosclerosis Risk in Communities (ARIC) Study. Am J Clin Nutr 105, 651-659.

18. Ruiz-Canela M \& Martínez-González MA (2014) Lifestyle and dietary risk factors for peripheral artery disease. Circ $J \mathbf{7 8}$, 553-559.

19. Najeeb S, Zafar MS, Khurshid Z, et al. (2016) The role of nutrition in periodontal health: an update. Nutrients $\mathbf{8}$, E530.

20. Milward M \& Chapple I (2013) The role of diet in periodontal disease. Clin Dent Health 52, 18-21.

21. Hujoel PP \& Lingstrom P (2017) Nutrition, dental caries and periodontal disease: a narrative review. J Clin Periodontol 44, Suppl. 18, S79-S84.

22. Sheiham A \& Steele J (2001) Does the condition of the mouth and teeth affect the ability to eat certain foods, nutrient and dietary intake and nutritional status amongst older people? Public Health Nutr 4, 797-803.

23. Beaudette JR, Fritz PC, Sullivan PJ, et al. (2017) Oral health, nutritional choices, and dental fear and anxiety. Dent J 5, 8. 
24. Staudte H, Kranz S, Volpel A, et al. (2012) Comparison of nutrient intake between patients with periodontitis and healthy subjects. Quintessence Int 43, 907-916.

25. Marcenes W, Steele JG, Sheiham A, et al. (2003) The relationship between dental status, food selection, nutrient intake, nutritional status, and body mass index in older people. Cad Saude Publica 19, 809-816.

26. Rooke TW, Hirsch AT, Misra S, et al. (2011) 2011 ACCF/AHA Focused update of the guideline for the management of patients with peripheral artery disease (updating the 2005 guideline): A Report of the American College of Cardiology Foundation/American Heart Association Task Force on Practice Guidelines Developed in Collaboration With the Society for Cardiovascular Angiography and Interventions, Society of Interventional Radiology, Society for Vascular Medicine, and Society for Vascular Surgery. J Vasc Surg 54, e32-e 58

27. American Dental Association, American Academy of Periodontology \& Procter \& Gamble Company (2001) Periodontal Screening \& Recording: An Early Detection System. Chicago, IL: American Dental Association.

28. Landry RG \& Jean M. (2002) Periodontal Screening and Recording (PSR) Index: precursors, utility and limitations in a clinical setting. Int Dent J 52, 35-40.

29. Freisling H, Elmadfa I, Schuh W, et al. (2009) Development and validation of a food frequency index using nutritional biomarkers in a sample of middle-aged and older adults. J Hum Nutr Diet 22, 29-39.

30. German Society for Nutrition, Österreichische Gesellschaft für Europapolitik, Swiss Society for Nutrition Research, Swiss Association for Nutrition (D-A-CH) (2016) Referenzwerte für die Nährstoffzufubr. 2. Korrigierte Auflage ed. (Reference Levels for Nutrient Intake. 2. Corrected edition). Umschau: Neuer Umschau Buchverlag GmbH.

31. Piepoli MF, Hoes AW, Agewall S, et al. (2016) 2016 European Guidelines on cardiovascular disease prevention in clinical practice: The Sixth Joint Task Force of the European Society of Cardiology and Other Societies on Cardiovascular Disease Prevention in Clinical Practice (constituted by representatives of 10 societies and by invited experts) Developed with the special contribution of the European Association for
Cardiovascular Prevention \& Rehabilitation (EACPR). Eur Heart J 37, 2315-2381.

32. Eckel RH, Jakicic JM, Ard JD, et al. (2014) 2013 AHA/ACC guideline on lifestyle management to reduce cardiovascular risk. Circulation 129, 25 Suppl. 2, S76-S99.

33. Kris-Etherton PM (2002) Fish consumption, fish oil, omega-3 fatty acids, and cardiovascular disease. Circulation 106, $2747-2757$.

34. Smith SC, Jr., Benjamin EJ, Bonow RO, et al. (2011) AHA/ACCF Secondary Prevention and Risk Reduction Therapy for Patients with Coronary and Other Atherosclerotic Vascular Disease: 2011 update: a guideline from the American Heart Association and American College of Cardiology Foundation. Circulation 124, 2458-2473.

35. Bland JM \& Altman DG (1995) Multiple significance tests: the Bonferroni method. BMJ 310, 170.

36. Ahn YB, Shin MS, Han DH, et al. (2016) Periodontitis is associated with the risk of subclinical atherosclerosis and peripheral arterial disease in Korean adults. Atherosclerosis 251, 311-318.

37. Lages EJ, Costa FO, Cortelli SC, et al. (2015) Alcohol consumption and periodontitis: quantification of periodontal pathogens and cytokines. J Periodontol 86, 1058-1068.

38. Bell S, Daskalopoulou M, Rapsomaniki E, et al. (2017) Association between clinically recorded alcohol consumption and initial presentation of 12 cardiovascular diseases: population based cohort study using linked health records. BMJ 356, j909.

39. Hamasaki T, Kitamura M, Kawashita Y, et al. (2017) Periodontal disease and percentage of calories from fat using national data. J Periodontal Res 52, 114-121.

40. Elmadfa I (2012) Österreichischer Ernährungsbericht 2012. 1. Auflage ed. (Austrian Nutrition Report 2012. 1. Corrected ed.). Vienna: Institut für Ernährungswissenschaften Universität Wien.

41. Ruiz-Canela M, Estruch R, Corella D, et al. (2014) Association of Mediterranean diet with peripheral artery disease: The PREDIMED randomized trial. JAMA 311, 415-417.

42. Naqvi AZ, Buettner C, Phillips RS, et al. (2010) n-3 Fatty acids and periodontitis in US adults. J Am Diet Assoc 110, $1669-1675$. 